\title{
Papel de los departamentos y cátedras de educación médica en los centros académicos
}

\author{
Madalena Patricio
}

Los docentes deben hacer frente a un amplio rango de retos educativos, que incluye la aparición de nuevos conocimientos, las nuevas tecnologías de la educación, el aumento de las expectativas públicas, los nuevos derechos y demandas de los pacientes, la especialización del saber médico, la necesidad de formar nuevos profesionales, los cambios de los estudiantes que se han formado con Internet y la tendencia social hacia una mayor responsabilidad.

En vista de todos estos retos, y como respuesta a la presión y a las mayores demandas a las que tienen que hacer frente los docentes, actualmente la educación médica, como materia especial que es, goza cada vez más de un mayor prestigio. Debería enseñarse a todos los profesores 'cómo enseñar' y quizá así algunos de ellos desarrollasen un interés en particular por la educación médica, con vistas a promover una investigación y un desarrollo mayores en este campo.

Para lograr estos objetivos, numerosas universidades han creado departamentos de educación médica que pueden representar un 'hogar' para aquellos docentes que puedan estar particularmente interesados en dicha materia. Estos departamentos o unidades realizan actividades como las siguientes:

- Enseñanza: programas de formación de personal especializado en la educación médica, dirigidos a docentes, e iniciación de estudiantes en la enseñanza en una línea acorde con la nueva visión del General Medical Council.

- Investigación en el campo de la educación médica.

- Provisión de servicios: apoyo para la planificación del currículo, nuevos métodos de enseñanza y asesoramiento, etc.
- Desarrollo profesional del personal: promocionar y dar apoyo al personal que en un futuro podrían constituir los nuevos educadores médicos.

Estos desarrollos no solamente tienen en cuenta la eficacia y la eficiencia de los conocimientos que se imparten en las facultades de medicina, sino que también velan para que los nuevos paradigmas y los nuevos puntos de vista de la educación médica sean los adecuados para afrontar los retos mencionados anteriormente.

Como cualquier otra iniciativa desarrollada en una facultad de medicina, la creación de un departamento de educación médica requiere una implicación a todos los niveles, de arriba abajo y viceversa, es decir, el apoyo de los decanos y la participación de los docentes, los estudiantes y demás partes implicadas.

La AMEE (International Association for Medical Education) reconoce que un departamento de educación médica es cada vez más un requisito imprescindible en las facultades de medicina. Su reconocimiento en el seno de la institución constituye un factor clave para propiciar los cambios que se precisan con el fin de lograr la excelencia en la educación médica.

\section{Bibliografía}

1. Davis MH, Karunathilake I, Harden RM. The development and role of departments of medical education: AMEE Education Guide no 28. Med Teach 2005; 27: 665-75.
Presidenta de la AMEE (International Association for Medical Education). Instituto de Introducción a la Medicina. Centro de Medicina Basada en la Evidencia. Facultad de Medicina. Universidad de Lisboa.

E-mail patricio@fm.ul.pt 